\title{
Traumatic Posterior Fossa Epidural Hematomas in Children : Experience with 48 Cases and a Review of the Literature
}

\author{
You Chaoguo, M.M., Long Xiu, M.M., Hu Liuxun, M.M., Sheng Hansong, M.D., Zhang Nu, M.D. \\ Department of Neurosurgery, The Second Affiliated Hospital and Yuying Children's Hospital of Wenzhou Medical University, Wenzhou, China
}

Objective : Epidural haematoma (EDH) most commonly occurs in the supratentorial area, particularly in the temporal region, of the brain. Posterior fossa epidural haematoma (PFEDH) is less frequently observed, accounting for only $1.2 \%$ to $12.9 \%$ of all EDH cases. Because of the non-specific symptoms and the potential for rapid and fatal deterioration in children, an early computed tomography (CT) scanning is necessary for all suspicious cases. The aim of the present study was to share the experience of 48 cases and review the literature concerning PFEDH.

Methods : A retrospective analysis was conducted for 48 paediatric cases diagnosed with PFEDH and admitted to Yuying Children's Hospital of Wenzhou Medical University from January 2010 to August 2015. The clinical features and outcomes were analyzed and compared with previous literature.

Results : Seventeen patients were surgically treated in this series and 31 patients received non-operative treatment. The outcomes were good in 46 patients, evaluated using the Glasgow outcome score (GOS), while mild disability was observed in one patient, and only one case showed severe disability. There were no cases of mortality in this series.

Conclusion : Posterior fossa epidural haematoma is relatively rare compared with supratentorial epidural haematoma. Early and serial CT scans should be performed for all suspicious cases. The criteria for the surgical treatment of paediatric patients with PFEDH were concluded. The overall prognosis was excellent in paediatric patients.

Key Words : Cranial fossa $\cdot$ Posterior $\cdot$ Hematoma $\cdot$ Epidural $\cdot$ Traumatic $\cdot$ Child.

\section{INTRODUCTION}

An epidural haematoma (EDH) is most commonly occurs in the supratentorial area, particularly in the temporal region, of the brain. Posterior fossa epidural haematoma (PFEDH) is less frequently observed, accounting for only $1.2 \%$ to $12.9 \%$ of all EDH cases ${ }^{2,10,21,23)}$. Because of the non-specific symptoms and the potential for rapid and fatal deterioration in children, an early computed tomography (CT) scanning is necessary for all suspicious $\operatorname{cases}^{21,23)}$. Although surgical evacuation is suitable for most PFEDH patients, some patients without mass effect can be conservatively treated ${ }^{21,23)}$. Several studies have reported good outcomes of PFEDH in children ${ }^{1,2,6-8,10,17,23)}$. The aim of the present study was to analyse the outcomes of 48

- Received : June 2, 2016 •Revised : September 30, 2016 •Accepted : January 9, 2017

- Address for reprints : Zhang Nu, M.D.

Department of Neurosurgery, The Second Affiliated Hospital and Yuying Children's Hospital of Wenzhou Medical University, 109 Xueyuan Road, Wenzhou, Zhejiang 325027, China

Tel : +86-13676458782, Fax : +86-057788832693, E-mail : zhangnu63@163.com

This is an Open Access article distributed under the terms of the Creative Commons Attribution Non-Commercial License (http://creativecommons.org/licenses/by-nc/4.0) which permits unrestricted non-commercial use, distribution, and reproduction in any medium, provided the original work is properly cited. 
paediatric patients with PFEDH at the Children's Trauma Centre and review this child age group in the literature.

\section{MATERIALS AND METHODS}

In total, 647 cases with traumatic EDH were admitted to the hospital within a period of 6 years (2010-2015); among which, 336 patients were less than 18 years of age. Among these 336 patients, a total of 48 paediatric cases of PFEDH were identified. The clinical data obtained from the medical and radiographic records were retrospectively analysed. We recorded the demographic data, trauma type, clinical signs and symptoms, CT findings, treatment type, and outcomes. This study was approved by the Regional Ethics Committee of the Second Affiliated Hospital of Wenzhou Medical University and all patients signed informed consents.

The Glasgow coma scale (GCS) was used to assess the level of consciousness at presentation and during and after treatment. Upon admission, CT scans were obtained for all suspicious patients with a history of head injury. We evaluated the CT findings, including the volume of the haematoma, the presence of fourth ventricle compression, the hydrocephalus and obliteration of the perimesencephalic cistern, the presence and pattern of the skull fracture, and the associated intracranial lesions. The decision for surgical or expectant treatment primarily depended on the CT findings and the clinical condition of the patients. The criteria for surgical intervention included a clot volume $\geq 15 \mathrm{~mL}$ or the presence of fourth ventricle compression or displacement and/or obstructive ventriculomegaly. Patients with small haematomas (volume $<10 \mathrm{~mL}$ ) without mass effects and no associated intracranial lesions or midline shift were conservatively treated. Treatment was individualised based on the clinical condition of the patients, i.e., a haematoma volume ranging from 10 to $15 \mathrm{~mL}$. At follow up, the outcome was evaluated using the Glasgow outcome scale (GOS). The patients were classified into five groups according to the GOS : 5 (good recovery), 4 (moderate disability), 3 (severe disability), 2 (persistent vegetative state), or 1 (death).

Upon admission, an emergency physician conducted a rapid and accurate examination of all patients, which included an assessment of the level of consciousness and pupillary reactivity. Further medical treatment included respiratory support with mechanical ventilation, treatment of fluid resuscita- tion, treatment of haemorrhage and associated substantial extra cranial injury, as appropriate.

Each patient underwent a CT plain scan and careful examination by an experienced trauma team (comprising trauma surgeons, anaesthesiologists, radiologists and nurses). Depending on the CT findings and the clinical condition, patients underwent surgery and/or were admitted to the paediatric intensive care unit (PICU) or paediatric ward. Patients requiring close observation were admitted to PICU, and neurological monitoring was performed, with hourly GCS and pupillary examinations. Consecutive follow-up CT scans were routinely performed after injury, particularly within the first 72 hours of hospital admission. Treatment was individualised from patient to patient.

Trauma surgeons provided neurosurgery in consultation with neurosurgeons for complicated issues. Anaesthesiologists in cooperation with trauma surgeons and neurosurgeons were responsible for the intensive care. Neurosurgeons in cooperation with radiologists interpreted the CT scan findings. For patients with surgical indications, the standard surgery, suboccipital craniectomy, was immediately performed. During the postoperative period, all patients routinely underwent a CT scan within 6 hours to assess the completeness of evacuation and/or resolution of the fourth ventricle compression.

\section{RESULTS}

With a mean age of 5.42 years ranging from 6 months to 16 years, 24 boys and 24 girls with a male-to-female ratio of $1: 1$ were examined in the present study. The most common cause of PFEDH was a fall from a height in 38 patients (79.2\%), and 10 patients were victims of motor vehicle accidents $(20.8 \%)$. Thirty-six patients (75\%) were admitted within 24 hours of injury, 11 patients (22.9\%) were admitted within 48 hours of injury, and one patient was brought to the hospital within 72 hours of injury.

The mean GCS score upon admission of this series was 13 (ranging from 4 to 15). A total of 36 patients (75\%) were admitted to the centre with the GCS scores of 13-15, seven patients (14.6\%) were admitted with the GCS scores of 9-12, four patients (8.3\%) were admitted with the GCS scores of 6-8, and only one patient $(2.1 \%)$ was admitted with a GCS score of less than 5 . The most common symptoms were vomiting and head- 
Table 1. Summary of clinical data in children with PFEDH

\begin{tabular}{|c|c|c|c|}
\hline \multirow[b]{2}{*}{ Clinical data } & \multicolumn{3}{|c|}{ No. of patients (\%) } \\
\hline & Operation & $\begin{array}{c}\text { Non- } \\
\text { operation }\end{array}$ & Total \\
\hline \multicolumn{4}{|l|}{ Cause of injury } \\
\hline Falls & 10 & 28 & $38(79.2)$ \\
\hline Motor vehicle accident & 7 & 3 & $10(20.8)$ \\
\hline \multicolumn{4}{|l|}{ Admission GCS score } \\
\hline $3-8$ & 5 & 0 & $5(10.4)$ \\
\hline $9-12$ & 7 & 0 & $7(14.6)$ \\
\hline $13-15$ & 5 & 31 & $36(75)$ \\
\hline \multicolumn{4}{|l|}{ Symptoms and signs } \\
\hline Vomiting & 13 & 10 & $23(47.9)$ \\
\hline Headache & 5 & 20 & $25(52.1)$ \\
\hline Loss of consciousness & 5 & 0 & $5(10.4)$ \\
\hline Drowsiness & 6 & 0 & $6(12.5)$ \\
\hline Asymptomatic & 0 & 7 & $7(14.6)$ \\
\hline Mean volume of hematoma $(\mathrm{mL})$ & 18.3 & 6.2 & 10.5 \\
\hline Range & $10-28$ & $3-13$ & $3-28$ \\
\hline \multicolumn{4}{|l|}{ Associated lesions } \\
\hline Occipital bone fracture & 14 & 24 & $38(79.2)$ \\
\hline Contusion & 8 & 3 & $11(22.9)$ \\
\hline Subarachnoid hemorrhage & 2 & 2 & $4(8.3)$ \\
\hline \multicolumn{4}{|l|}{ Mass effect } \\
\hline $\begin{array}{l}\text { Compression or displacement } \\
\text { of the fourth ventricle }\end{array}$ & 8 & 0 & $8(16.7)$ \\
\hline Ventricular dilation & 5 & 0 & $5(10.4)$ \\
\hline
\end{tabular}

PFEDH : posterior fossa epidural haematoma, GCS : Glasgow coma scale ache, presenting in $23(47.9 \%)$ and $25(52.1 \%)$ patients, respectively. A total of five cases (10.4\%) had the temporary loss of consciousness and seven cases (14.6\%) were asymptomatic.

The volume of the haematomas varied from 3 to $28 \mathrm{~mL}$. The mean volume of the clot was $6.2 \mathrm{~mL}$ (ranging from 3 to $13 \mathrm{~mL}$ ) in conservatively treated patients, and $18.3 \mathrm{~mL}$ (10-28 $\mathrm{mL}$ ) in surgically treated patients. Occipital bone fractures were observed in 38 patients (79.2\%), and multiple intracranial injuries were present in 21 patients (43.8\%). Unilateral haematomas were detected in a majority of children with PFEDH, and bilateral haematomas were present in three patients in this series. Compression or displacement of the fourth ventricle was observed in eight cases, and ventricular dilation was observed in five cases. The clinical data for children with PFEDH are summarised in Table 1.

We operated on 17 patients : 14 patients underwent immediate surgery after diagnosis, and three patients, initially planned for conservative management, deteriorated in consciousness during hospitalisation. At surgery, 11 patients bled from the fracture lines, and no evidence of the source of bleeding was observed in six patients (Fig. 1). There were no cases of mortality among the surgically treated patients. Thirty-one patients were conservatively managed (Fig. 2), undergoing close observation of their neurological status and serial CT scanning (at 24, 48, and 72 hours after admission).

Except for two cases, all patients had good recovery after a mean hospital stay of 5.4 days. The mean follow-up duration was 14.3 months (ranging from 3 to 24 months). The GOS was
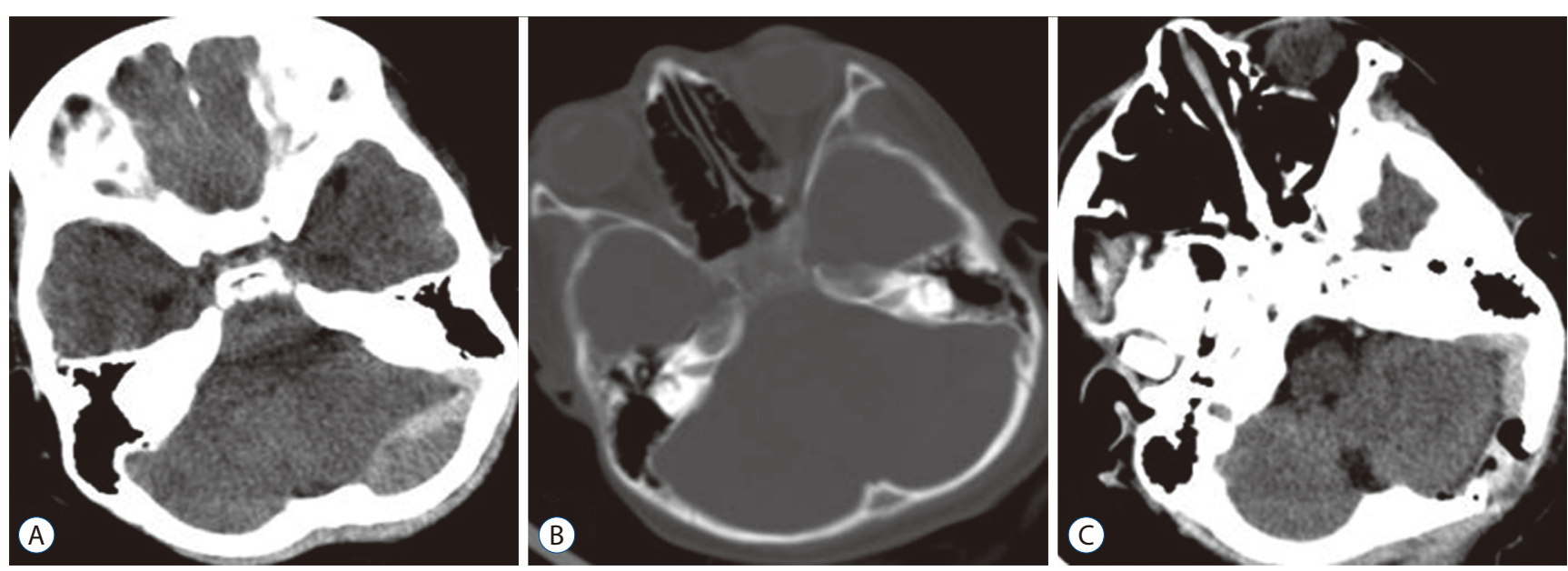

Fig. 1. Case of a 10-year-old girl with surgically managed PFEDH. A : Preoperative CT scans showing a large, left-sided, mixture density haematoma with a significant mass effect. B : Bony windows showing that an occipital bone fracture was not detected. $\mathrm{C}:$ A postoperative image showing the near complete evacuation of the haematoma. PFEDH : posterior fossa epidural haematoma, CT : computed tomography. 

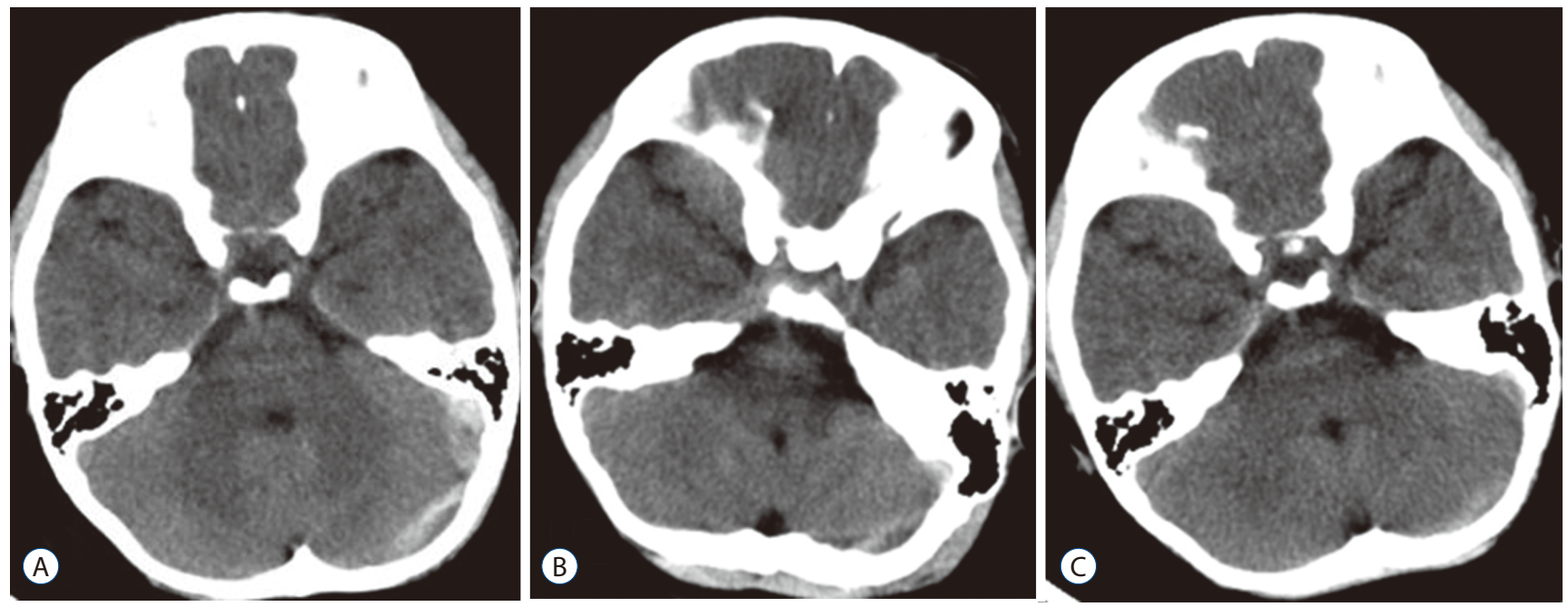

Fig. 2. Case of a 5-year-old boy with conservatively managed PFEDH. A : Plain CT at admission revealing two PFEDH on the left side without mass effects. B : Follow-up CT after 48 hours showing a slight reduction of the haematoma. C : Repeat scan after 6 days showing the almost complete absorption of the haematoma. PFEDH : posterior fossa epidural haematoma, CT : computed tomography.

Table 2. Summary of the outcome of patients with PFEDH

\begin{tabular}{lcccc}
\hline & \multicolumn{4}{c}{ Outcome } \\
\cline { 2 - 5 } & Good & Mild & Death & $\begin{array}{c}\text { No. of } \\
\text { patients }\end{array}$ \\
\hline Suigical treatment & 15 & 2 & - & 17 \\
Conservative management & 31 & - & - & 31 \\
\hline
\end{tabular}

PFEDH : posterior fossa epidural haematoma

used to assess the neurological outcomes. Patients whose score was 5 or 4 were classified as having a good outcome, and those with a score between 1 and 3 were classified as having a poor outcome. The GOS showed that 46 patients had good outcomes, while one patient had a moderate disability but was independent (GOS 4), and one patient had a disability (GOS 3). No mortalities were observed in this series. The outcomes for children with PFEDH are summarised in Table 2.

\section{DISCUSSION}

Traumatic PFEDH is an uncommon entity ${ }^{2,10,21,23)}$. After the introduction of CT scanning, the incidence of PFEDH has increased during childhood, but few clinical reports have been generated in the literature in the past two decades ${ }^{2,6,8,10,21,233}$. This institution is a secondary trauma centre, which is also a professional and experienced paediatric trauma unit in a medium- sized city with approximately 600 cases of head trauma annually, 9.3\% of paediatric-age patients with epidural haematomas and traumatic PFEDHs in children, accounting for $1.5 \%$ of all patients. Compared with the data in previous studies, this series contained significantly more patients with delayed admissions. Twelve (25\%) of the patients examined in the present study were admitted after the first 24 hours. Most of these patients were referred to the hospital because of haematoma enlargement and/ or clinical deterioration, as the patients were conservatively treated in small local hospitals or private clinics. In addition, there were a few patients for whom direct transport was not possible, reflecting the proximity of the trauma centre.

The most common cause of PFEDHs in children is a fall, as $78.7 \%$ of the patients had a history of a fall in the present study, consistent with previous reports in this age group ${ }^{2,10,21,23)}$. Motor vehicle accidents, which most often occur with older children, accounted for $21.3 \%$ of the PFEDH patients examined in the present study. The findings revealed an age distribution ranging from 6 months to 16 years, with a mean of 5.4 years. Older children were predominantly affected, and the occurrence of PFEDH in children $<3$ years was extremely rare ${ }^{2,10,21,23)}$. Unfortunately, two infants were observed among these patients, a 6-month-old boy and a 7-month-old girl. Both patients presented with a PFEDH after a fall from a height and were operatively treated.

According to the presentation and duration of clinical manifestations, the clinical course in PFEDH can be classified into 

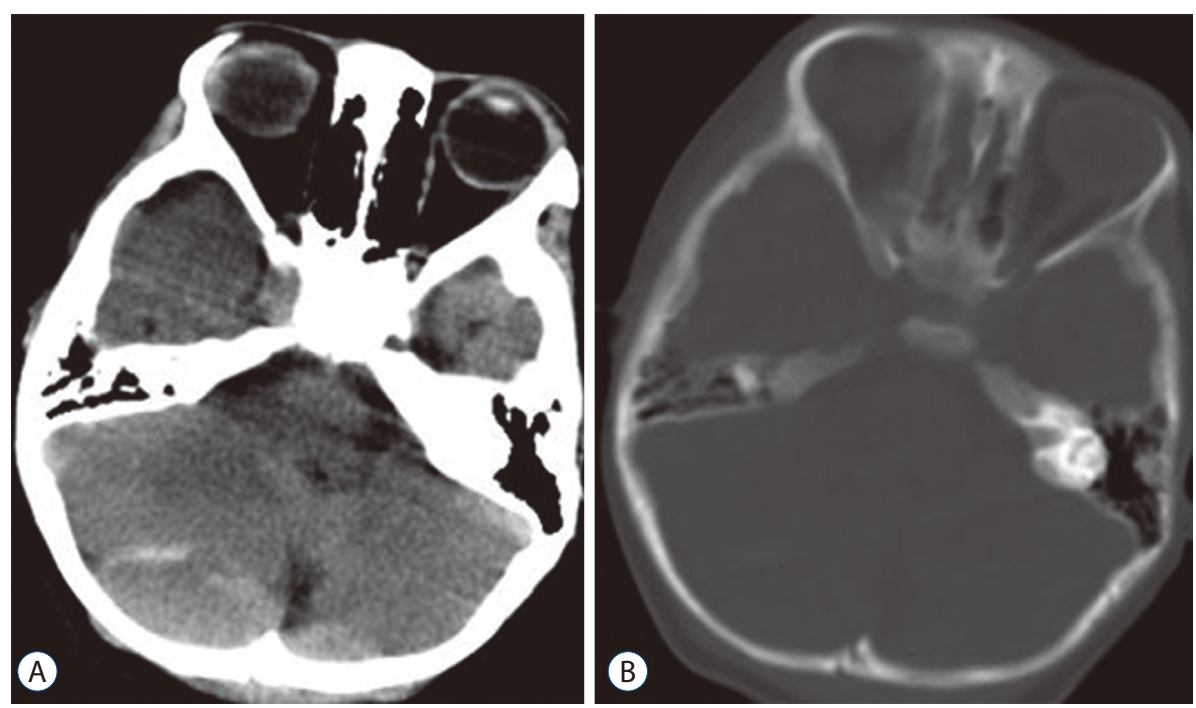

Fig. 3. Case of a 3-year-old child with surgically managed bilateral PFEDH (A) with a linear fracture of the occipital bone (B). PFEDH : posterior fossa epidural haematoma.

acute ( $<24$ hours), subacute (up to 7 days) and chronic $(>7$ days ${ }^{10,12,18)}$. Subacute and chronic haematomas have rarely been documented in previous literature ${ }^{2,10,18,21,23)}$. In the present study, all patients were acute, and the majority of patients with PFEDH initially presented with mild symptoms that gradually progressed ${ }^{5)}$. Typically, occipital trauma is associated with severe headache and vomiting, marked with alterations in the state of consciousness and, occasionally, a lucid interval. Vomiting and headache were the most common manifestations observed in the present series, consistent with previous reports ${ }^{2,10,23)}$. A majority of the cases in the published series involved mild head injuries (GCS, 13-15). Cases of severe head injury (GCS, 3-8) have been uncommonly reported in previous literature ${ }^{1,2,10,21,23)}$. Indeed, we observed 36 mild, seven moderate and five severe head injuries in the present series. Consistent with other authors, we also suggest that the GCS score upon admission is the main determinant of the outcome in children with PFEDH. Based on these data and the good outcomes observed in the present series, we propose that good GCS scores indicate a favourable prognosis. Lucid interval is classically observed in EDH; however, this feature is uncommon in paediatric PFEDHs. Only 11 patients (22.9\%) were observed in the present study, and a lucid interval was more often observed in patients with associated supratentorial lesions ${ }^{10)}$. In addition, patients with associated supratentorial lesions in PFEDH also present other complications including contusions, diffuse oedema and subarachnoid haemorrhage. In the present study, we observed such supratentorial lesions in 12 of the 48 cases (25\%) examined, which was similar to other reports ${ }^{21,23,24)}$.

A non-contrast CT, which detects an occipital skull fracture, the volume and location of haematomas, and associated supratentorial lesions, is a useful imaging tool for evaluation in $\mathrm{PFEDH}^{18,23)}$. Because the CT findings are generally found earlier than the clinical manifestations, the diagnosis rate increases $^{4)}$. Hence, we advise that upon admission, CT scans be obtained in all suspicious patients who have a history of head injury. Furthermore, we routinely performed consecutive follow-up CT scans in conservatively treated cases, particularly within the first 72 hours of hospital admission.

The incidence of occipital skull fractures associated with paediatric PFEDHs, such as Sencer et al.'s3) ${ }^{23)}$ series (87.5\%) and Prasad et al.'s ${ }^{21)}$ series (72.7\%), has been frequently published in the literature. An occipital bone fracture was identified in almost $79.2 \%$ of the patients examined in the present study. The presence of an occipital fracture has been considered the most reliable indicator for the development of haematomas. However, Harwood-Nash et al. ${ }^{11)}$ reported that only $3 \%$ of the children with occipital fractures developed PFEDH. The incidence of bilateral haematomas is a relatively infrequent finding, particularly in cases of midline bone fracture and dural venous sinus injury ${ }^{10)}$. Bilateral haematomas were detected in $6.3 \%$ of the cases examined in the present study, which is consistent with other reports (Fig. 3) ${ }^{10,16)}$. Hydrocephalus may occur when there is a remarkable mass effect in the posterior fossa. The incidence of hydrocephalus or ventricular dilation is uncommon in paediatric PFEDHs, and the presence of hydrocephalus on a CT scan is an ominous sign for poor prog- 
Table 3. Summary of surgical indications of patients with PFEDH in the literature

\begin{tabular}{|c|c|}
\hline Article & Surgical Indication \\
\hline Ciurea et al. (1993) & Surgical treatment must be carried out immediately when the diagnosis has been established. \\
\hline Ersahin and Mutluer (1993) & $\begin{array}{l}\text { Once the diagnosis of a posterior fossa extradural hematoma is made, the symptomatic hematomas should be } \\
\text { evacuated immediately. }\end{array}$ \\
\hline Gupta et al. $(2002)^{10)}$ & $\begin{array}{l}\text { Hematoma more than } 10 \mathrm{~mL} \text { in volume, more than } 15 \mathrm{~mm} \text { in thickness, with a midline shift of more than } 5 \mathrm{~mm} \text {, } \\
\text { medullary compression and associated intracranial lesions. }\end{array}$ \\
\hline Berker et al. $(2003)^{2)}$ & $\begin{array}{l}\text { When the diagnosis is established, surgery should be performed as soon as possible even if the neurological examination } \\
\text { is normal. }\end{array}$ \\
\hline Sencer et al. $(2012)^{23)}$ & $\begin{array}{l}\text { a hematoma thickness of greater than } 15 \mathrm{~mm} \text { or the hematoma thickness varied between } 5 \text { and } 15 \mathrm{~mm} \text { with injuries/ } \\
\text { conditions (for instance, a contusion, pneumocephalus, or SAH) causing additional mass effect or a GCS score less than } \\
15 \text {. }\end{array}$ \\
\hline Prasad et al. $(2015)^{21)}$ & $\begin{array}{l}\text { A hematoma with a volume of }>20 \mathrm{~mL} \text { or radiological evidence of posterior fossa mass effect in the form of fourth- } \\
\text { ventricle distortion or compression and/or obstructive ventriculomegaly, irrespective of the GCS score. }\end{array}$ \\
\hline This study (2016) & Clot volume $\geq 15 \mathrm{~mL}$ or presence of fourth ventricle compression or displacement and/or obstructive ventriculomegaly. \\
\hline
\end{tabular}

PFEDH : posterior fossa epidural haematoma, SAH : subarachnoid hemorrhage, GCS : Glasgow coma scale

nosis $^{2,3,6,15,16,20,22)}$. In the present study, five of the patients examined had hydrocephalus, while Sencer et al. ${ }^{23)}$ observed hydrocephalus in six cases, and Prasad et al. ${ }^{21)}$ did not observe any cases of hydrocephalus. In these cases, hydrocephalus was resolved immediately after surgery.

The traditional treatment of PFEDH is surgical evacuation $^{1,2,9,10)}$, although an increasing number of patients are currently conservatively treated ${ }^{21,23)}$. The criteria for an early surgical management or conservative treatment remain unclear $^{1,4,14)}$. Table 3 summarises the surgical indications of the available major cases of children with PFEDH in the literature. The majority of studies list surgical indications, such as a haematoma volume $>10 \mathrm{~mL}$, a midline shift $>5 \mathrm{~mm}$, the obliteration of perimesencephalic cisterns, the displacement of the fourth ventricle and the presence of hydrocephalus ${ }^{3,4,8,10,16,19,20,23,25)}$. However, in 2015, Prasad et al. ${ }^{21)}$ examined 22 cases of paediatric PFEDH and concluded that patients who underwent a CT scan showing a haematoma volume $>20 \mathrm{~mL}$ and/or fourth-ventricle mass effect with/without ventriculomegaly should undergo surgery. In addition, Sencer et al. ${ }^{23)}$ suggested that haematoma thickness instead of volume should be used as a critical surgical criterion, and all patients with a haematoma thickness of less than $5 \mathrm{~mm}$ were followed up conservatively in the 40 cases examined. In the present study group, all patients with a haematoma volumes $\geq 15 \mathrm{~mL}$ or the presence of fourth ventricle compression or displacement and/or obstructive ventriculomegaly were immediately surgically evacuated. During the operation, 11 pa- tients had bleeding from fracture lines, and no evidence of the source of bleeding was observed in six patients. There were no mortalities among the surgically treated patients. In addition, enlarging haematomas and neurological deterioration are indications for surgical management ${ }^{23)}$. A total of three patients were initially conservatively managed but deteriorated in consciousness during hospitalisation. Thus, we recommend, based on experience, immediate evacuation in patients with indications for surgical intervention, as these individuals may rapidly deteriorate, worsening their prognosis. Thirty-one patients were conservatively managed by close observation and serial imaging, as these patients had normal neurological statuses, and the admission CT scans showed a small haematomas without significant mass effects.

Previous studies have suggested that the prognosis for children with PFEDH is good ${ }^{1,2,10,13,21,23)}$. For instance, Prasad et al. $^{21)}$, in a series of 22 children with PFEDH, reported that all patients had good outcomes, except one case of moderate disability. Sencer et al. ${ }^{23)}$ reported 40 cases of patients with good outcomes. Gupta et al. ${ }^{10)}$ reported one case of severe disability and two cases of moderate disability among the 19 children PFEDH examined in their study. Berker et al. ${ }^{2)}$ reported a single case of mortality and one case of moderate disability among 16 children with PFEDH. In the present study, 35.4\% of the patients received surgical treatment, and $64.6 \%$ of the patients were conservatively followed up. The majority of these patients had good outcomes; one patient had a moderate disability, but was independent (GOS 4); and one patient had a 
disability (GOS 3). There were no mortalities observed among this study population. Thus, to reduce the morbidity and mortality, we suggest that surgical removal should never be delayed when a haematoma has been indicated.

\section{CONCLUSION}

PFEDH is relatively rare compared with supratentorial epidural haematoma. Early and serial CT scans should be performed for all suspicious cases. The criteria for the surgical treatment for paediatric patients of PFEDH have been described, and the overall prognosis was excellent in paediatric patients.

\section{CONFLICTS OF INTEREST}

No potential conflict of interest relevant to this article was reported.

\section{INFORMED CONSENT}

Informed consent was obtained from all individual participants included in this study.

\section{References}

1. Ammirati $M$, Tomita $T$ : Posterior fossa epidural hematoma during childhood. Neurosurgery $14:$ 541-544,1984

2. Berker M, Cataltepe O, Ozcan OE : Traumatic epidural haematoma of the posterior fossa in childhood: 16 new cases and a review of the literature. Br J Neurosurg 17 : 226-229, 2003

3. Bor-Seng-Shu E, Aguiar PH, de Almeida Leme RJ, Mandel M, Andrade AF, Marino R Jr : Epidural hematomas of the posterior cranial fossa. Neurosurg Focus 16 : ECP1, 2004

4. Bozbuğa M, Izgi N, Polat G, Gürel I : Posterior fossa epidural hematomas: observations on a series of 73 cases. Neurosurg Rev $22: 34-40$ 1999

5. Bullock MR, Chesnut R, Ghajar J, Gordon D, Hartl R, Newell DW, et al. Surgical management of posterior fossa mass lesions. Neurosurgery 58 : S47-S55; discussion Si-Siv, 2006

6. Ciurea AV, Nuteanu L, Simionescu N, Georgescu S : Posterior fossa extradural hematomas in children: report of nine cases. Childs Nerv Syst 9 : 224-228, 1993

7. Costa Clara JM, Claramunt E, Ley L, Lafuente J : Traumatic extradural hematomas of the posterior fossa in children. Childs Nerv Syst 12 : 145-148, 1996

8. Ersahin Y, Mutluer $S$ : Posterior fossa extradural hematomas in children. Pediatr Neurosurg 19 : 31-33, 1993

9. Garza-Mercado R : Extradural hematoma of the posterior cranial fossa. Report of seven cases with survival. J Neurosurg 59 : 664-672, 1983

10. Gupta PK, Mahapatra AK, Lad SD : Posterior fossa extradural hematoma. Indian J Pediatr 69 : 489-494, 2002

11. Harwood-Nash DC, Hendrick EB, Hudson AR : The significance of skull fractures in children. A study of 1,187 patients. Radiology 101 : 151156, 1971

12. Hooper RS : Extradural haemorrhages of the posterior fossa. Br J Surg 42 : 19-26, 1954

13. Jung SW, Kim DW : Our experience with surgically treated epidural hematomas in children. J Korean Neurosurg Soc 51 : 215-218, 2012

14. Karasu A, Sabanci PA, Izgi N, Imer M, Sencer A, Cansever T, et al. : Traumatic epidural hematomas of the posterior cranial fossa. Surg Neurol 69 : 247-251; dicussion 251-252, 2008

15. Lui TN, Lee ST, Chang CN, Cheng WC : Epidural hematomas in the posterior cranial fossa. J Trauma 34 : 211-215, 1993

16. Malik NK, Makhdoomi R, Indira B, Shankar S, Sastry K : Posterior fossa extradural hematoma: our experience and review of the literature. Surg Neurol 68 : 155-158; discussion 158, 2007

17. Mori K, Handa H, Munemitsu H, Oda Y, Hashimoto N, Kojima M : Epidural hematomas of the posterior fossa in children. Childs Brain 10 : 130-140, 1983

18. Neubauer UJ : Extradural haematoma of the posterior fossa. Twelve years experiences with CT-scan. Acta Neurochir (Wien) 87 : 105-111, 1987

19. Otsuka S, Nakatsu S, Matsumoto S, Sato S, Motozaki T, Ban S, et al. : Study on cases with posterior fossa epidural hematoma--clinical features and indications for operation. Neurol Med Chir (Tokyo) 30 : 24-28, 1990

20. Pozzati $E$, Tognetti F, Cavallo $M$, Acciarri $N$ : Extradural hematomas of the posterior cranial fossa. Observations on a series of 32 consecutive cases treated after the introduction of computed tomography scanning. Surg Neurol 32 : 300-303, 1989

21. Prasad GL, Gupta DK, Sharma BS, Mahapatra AK : Traumatic pediatric posterior fossa extradural hematomas: a tertiary-care trauma center experience from India. Pediatr Neurosurg 50 : 250-256, 2015

22. Roda JM, Giménez $D$, Pérez-Higueras $A$, Blázquez MG, Pérez-Alvarez $M$ : Posterior fossa epidural hematomas: a review and synthesis. Surg Neurol 19 : 419-424, 1983

23. Sencer A, Aras Y, Akcakaya MO, Goker B, Kiris T, Canbolat AT : Posterior fossa epidural hematomas in children: clinical experience with 40 cases. J Neurosurg Pediatr 9 : 139-143, 2012

24. Wang EC, Lim AY, Yeo TT : Traumatic posterior fossa extradural haematomas (PFEDH). Singapore Med J 39 : 107-111, 1998

25. Wong CW : The CT criteria for conservative treatment--but under close clinical observation--of posterior fossa epidural haematomas. Acta Neurochir (Wien) 126 : 124-127, 1994 